\title{
A Theoretical Analysis of the Communicative Significance of Proverbs in English Language
}

\author{
Dr. Mukhalad Malik \\ Department of EnglishCihan University/ Sulaimaniya
}

\begin{abstract}
Proverbs are used nowadays as an effective spoken or written tool of expressing various meanings and intentions. This paper aims to demonstrate the value of proverbs at various levels of communications through a representation of their basic features and their various intended meanings which they convey. It is mainly concerned with showing the communicative significance of proverbs (what they intend to convey) through relating them to the different speech acts they contain and through elaborating the multiple inherited meanings which they exhibit when used in any communicative situation. It can be clearly proved through this paper that proverbs are used as part of the communication process emphasising different values of didactic functions, moral aspects, knowledge, wisdom and more through the use of language, specifically, the various speech acts that they implicitly and explicitly have.
\end{abstract}

Key words: proverbs, speech acts, functions, meanings, communicative significance

\section{INTRODUCTION}

Proverbs are deemed as one of the important aspects in English which have received an increased attention in the various levels of language understanding, teaching and learning. In the broadest sense, they are hey are products of human thought about the reality of things, human attitudes, feelings and beliefs. Such a broad area of human experience has made proverbs universally accepted. The present article tackles the various speech acts which they implicitly or explicitly express and, hence, it is concerned ultimately with showing their intended meaning and their significance in communication. This is done theoretically through discussing in detail what proverbs are linguistically and what possible speech acts (intended meanings) which they may have. To get a better and a more comprehensive understanding of proverbs, the article is coloured with different groups of proverbs on society, justice, weather and other kinds. The reason behind quoting various kinds of proverbs is to elaborate and enhance the theoretical part of the paper and to show the communicative significance and value of proverbs when used in communication being an impressive and widely used tool of expression in language.

\section{DEFINITIONS OF PROVERBS}

There have been many attempts to illustrate comprehensively and concisely what proverbs are by many linguists, authors and those who are interested in the purposes of language commutation and intended meanings, yet no one of them can be said to have the most precise or most comprehensive (Moon, 1997: 2). According to Whiting (1983: 80), a proverb is: An expression which owing its birth to the people, testifies its origin in form and phrase. It expresses what is apparently a fundamental truth in a homely language, often ornamented, however, with alliteration and rhyme. It is usually short but need not be; it is usually true but need not be. Some have both literal and figurative meaning, either of which makes perfect sense; but more often they have one of the two. Norrick (1985:31) describes proverbs as "self -contained, pithy, traditional expressions with didactic content and fixed, poetic form ".By self -contained is meant that their grammatical units can't be replaced by other units e.g., the sentence " curiosity killed the cat " cannot be replaced by another phrase .The word pithy means that though They have fixed poetic forms, they are full of meaning or as he puts it "pregnant in meaning". They are also traditional because they are part of folklore and contain wisdom, truth, morals and traditional perspectives related to our everyday thoughts, feelings and needs (ibid: 36). The most important aspect when considering the definition of proverbs is the fact that in the essence it is a polysemantic unit ; that it may have two different types of meaning: Literal and Figurative. The literal meaning is the one that can be clearly recognized. The proverb "Like father, like son" for example, is said to have a literal reading since "father and son are alike". Whereas, the proverb" Blood is thicker than water" has a figurative meaning which can be interpreted differently from its literal meanings depending on the social context. The figurative meaning of this proverb is that members of the same family share stronger ties with each other than they do with others. The meaning of the whole proverb is completely different from the meaning of its constitutive parts. It can be clearly 
seen that as far as the linguistic aspect of proverbs is concerned, they may be a phrase, saying, sentence, statement or expression of the folk containing majorly certain specific cultural features and certain speech act whether direct or indirect. The representation of such cultural features and speech acts is manifested by proverbs through various communicative values and significance such as wisdom, truth, morals, experience, lessons, and advice concerning life (ibid: 37-38).

\section{THE SPEECH ACTS OF PROVERBS}

It is beyond dispute that the major scope and interest of pragmatics is investigation of the type of meaning that goes beyond what is said literally. That is, the type of meaning intended by the speaker when, for instance, using a proverb in certain situation and inferred by the hearer only in terms of the context in which this proverb is used. The uttering of a certain proverb may involve the performance of two interrelated acts (formal and intentional). The formal act is explicitly conveyed by the grammatical form. The latter is implicitly induced from the context. The most important act is the intentional one because it shows clearly how the utterance is "taken to be" as well it is the one that implies the type of meaning intended by the speaker. The intentional act is often performed by the proper used proverb (Stiles, 1980:234).Akmajian et al. (2001:387) proceed that it is so obvious that proverbs are not used both literally and directly; they are often employed both nonlinearly and indirectly because people usually avoid directing their audience and choose proverbs to soften the effect by distancing themselves from the advice or warning. This clearly shows that proverbs are basically to be interpreted within the scope of speech acts. The most important point to consider when discussing the issue of proverbs in terms of speech acts is the belief that when using proverbs in certain situation it does not mean at all that uttering words of that proverb but performing linguistic acts for a certain communicative purpose which is proper to the situation in which it is uttered (ibid). Ultimately proverbs are statements that function as deeds. To get a better view of the fact that proverbs are containers of various speech acts, it is possible to consider the following proverbs:

Rainbow in the morning gives you fair warning."

Under certain appropriate conditions, this proverb does not describe the weather state but he actually offers the listener or addressee a gentle warning (i.e., fair rain will be approaching). While enunciating this proverb, three interrelated acts are simultaneously involved: the lectionary, illocutionary and elocutionary acts (which are the major components of a speech act).The act of uttering the proverb "Rainbow in the morning gives you fair warning" is referred to as the locution.This act involves the issuing of a well-formed grammatical and meaningful sentence pronounced properly (i.e., the words artificially divorced on the context of utterance). The illocution refers to what is intended in saying this proverb, or what type of speech acts is meant by this proverb. In fact, this proverb is taken to be a fair warning. What this clearly means is the fact that this proverb has the indirect speech act of warning (Verschueren, 1999: 30). "Behind the cloud the sun is shining" This proverb can be said in the actual use of language although there may be no clouds at all in the sky. Depending on the situation (or more specifically on the social situation) it can be interpreted, pragmatically, as conveying the indirect speech act of fighting slavery and how finally people must be equal in rights treatment and the like. This proverb is cited by one of the American presidents (Eisenhower) who sought justice among people. Apparently, he used this proverb as a social tool for calling for justice expressing his hopes of the rise of justice and equality (Mieder, 2004: 183). "If You Can't Stand the Heat, Get out of the Kitchen.' The interpretation of this proverb is that if someone can't tolerate the pressures of a particular situation, he/ she should remove oneself from that situation. This proverb implicitly has the indirect speech act of advice where the use is totally nonliteral. Although there is an image of kitchen, it does not refer to kitchen but to an entirely a different issue. It should always be considered that proverbs are the representations of certain context of situation used in certain and specific communicative process. "Who refuses to submit to justice must not complain of oppressions" Pragmatically, this proverb involves the direct speech act of warning. Anyone who does not follow rules or violate them will be punished which he shouldn't complain of. This proverb, according to the communicative event in which it is proper to occur, is warning against anyone who thinks or even tries to think of violating rules, so it is an urge for people not to do so since if they do they will be punished (Norick, 1985: 6-7). What can be noticed from the interpretations of those different proverbs is the fact that they clearly to be taken indirectly, they include indirect speech act of warn, advice or call for applying justice. Consequently, the indirect speech acts is an important feature that various kinds of proverbs exhibit (ibid).

\section{THE POTENTIAL MEANINGS OF PROVERBS}

The speech acts of proverbs discussed in the previous section demonstrate that they have various messages to convey including advice, warning and so on. But what about the words from which proverbs are made? This section attempts at investigating the meanings of the words of proverbs so as to shed light on the various possibilities they have relying on the probable interpretations they may encounter. Proverbs are words combined together to form larger semantic units, which are encoded by the speaker and decoded by the hearer 
by means of their underlined knowledge of the language itself: what contrasts with what and what constituent structure the proverb has. Proverbs, in this sense, have their own conceptual meaning which is a basic component language is and that the conceptual meaning of nearly any item in any language is the same since the conceptual meaning is "a universal property of the mind"(Leech, 1980:13-15). However, this by all means, does not mean that all people show the same conceptual framework, since differences in age, education, etc. play the greatest role. The following proverb shows that the meaning of the key word 'evils' is the logical (or referential or denotative) meaning that no two speakers would differ about: "Of two evils choose the least." The possible interpretations of words that compose the entire conceptual meaning of proverbs have other important characteristics because of the fact that they are associated with ideas of human experience but only when they are used in certain communicative situation. This is termed 'associative meaning', which can be of several types of meanings, the most important of which are connotative, affective, stylistic and collocative meanings. This variety of associative meaning is as a result of the diversity of the individual experience.

\subsection{Connotative Meaning of Proverbs}

The connotative meaning of proverbs is their communicative value by virtue of what psychological or social properties of what the linguistic items within the proverb imply. In talking about connotative meaning, one is talking about "the real world experience one associates with an expression when one uses or hears it"(ibid.). The intended meaning of a proverb cannot be effective unless the words are "associated with certain characteristics of the items to which they refer"(Palmer, 1981: 92). For example, people have different ideas about 'women', whether good or bad; these ideas are reflected in proverbs they use by means of words that are frequently associated with 'evil' (and rarely with 'gentleness'). The following borrowed proverb from French into English connotes that the 'women' are the source of all evil: "Cherchez la femme." Many other factors determine the extent of connotative meaning in proverbs, most of that reflect the worldview adopted by individuals, societies and cultures. For example, the idea that a wise man is supposed to make use of his previous mistakes or failures can be expressed equally or differently from one culture to another depending on how the world is viewed by individuals. In the English culture, people, for instance, would refer to such an idea by resorting to the world of animals and the nature respectively: "A fox is not taken twice in the same snare.' Thus, connotations in proverbs are relatively determined by instability. What promotes this lack of stability more and more is the fact that connotations have indeterminate status. Leech (1980: 15) in this regard states that the "associative meaning is open-ended in the same way as our knowledge and beliefs about the universe are open-ended".

\subsection{Stylistic Meaning of Proverbs}

The stylistic meaning of proverbs is hugely manifested by the existence of some characteristics of style (e.g. permanent, temporal, etc.). The most important stylistic standards of proverbs are essentially related to the stylistic scopes of status which comprise different vehicles for expressing any item (of thought) in language (e.g. formality vs. informality, politeness vs. impoliteness, etc.). A large percentage of proverbs are informal in both senses as related to structure or situation:

'While the grass grows the steed starves."'

-Die with one's boot on / die in one's boot.

(= to die while still active in one's work). (Makkai, 1984: 79)

\subsection{Collocative Meaning of Proverbs}

Proverbs, as a literary style, frequently consist of the association of ideas due to collocation. Collocation could be normal or unusual. Writers use the latter type at times for creating stylistic effects to impress readers. Of course, "there are inevitably differences of opinion as to what represents an acceptable collocation in English"(Gairness and Redman, 1986: 37), or whether the semantic function of the collocated words in the proverb can be fully deducible from the meaning of the individual words. However, the collocations that we are referring to in the following proverbs are of the normal type, depending mainly on oppositeness of meaning and that no two persons would disagree about their validity:

"As you sow, so will you reap.",

\section{THE COMMUNICATIVE SIGNIFICANCE OF PROVERBS}

Regardless of the type of the speech act or the potential meaning that proverbs may have, the major and most important fact to be stated is that they have certain functions to achieve when they are used in certain communicative situation. Proverbs and proverbial sayings, with their communicative significance and value, have for centuries been equally popular with all nations due to the enormous significance and function which they intend to carry and due to the influence they have made. Their inspiring significance in communication, the teaching they give, which ranges from general truths of advice, warning and comments they offer on human experience, encourage humans to act and behave in certain ways. While trying to analyse the functions of 
proverbs it is a prerequisite to bear in mind how traditional proverbs carry on to be employed and function in modern world. "Doubtlessly traditional proverbs still play a significant role in today's speech, where they continue to be used to moralize, to instruct, to advise, and to reflect on everyday occurrences" (Mieder, 1993:58). Such old well known proverbs are often used in a different new manner, they are changed in order to be efficient in communication at various levels showing a variety of significant functions in society, conversation, interaction and so While discussing the significance of proverbs as far as their use in any communicative event is concerned, a crucial question is to be posited: why do people use proverbs at all? Or what is the significance of using proverbs in communication? It can be stated that proverbs don't usually function as mere poetic embellishments of speech, neither are they used to meet man's needs for philosophic phrase mongering. In fact their use has some practical functions and significance in various circumstances of everyday communication. According to Taylor 'Men buy and read collections of proverbs to awaken and enlarge reflections on the world and the nature of man, to suggest subjects for conversation, or to provide themselves with comment appropriate to situations in daily life' (Taylor, 1996: 45). It would not be an insufficient assumption to state that proverbs are used to convey the general human problems and concerns by means of traditional language. According to Mieder (1993: 11) 'By employing proverbs in our speech we wish to strengthen our arguments, express generalisations, influence or manipulate other people, rationalize our own shortcomings, question certain behavioral patterns, satirize social ills, poke fun at ridiculous situations'.It is not surprising that through the ages proverbs which have prevailed and contributed significantly to the English language still form a living part of it and thus can enrich our everyday conversations. They make the language a more vivid and powerful tool of communication.

A response receives an additional weight when we don't speak merely with our own mouths and we don't use our individual expression of state of mind, but a general opinion. Indeed, the communicative significance of proverbs is various and plays multiple roles in any piece of communication. For instance, proverbs can be used to manoeuvre people politically and economically and they may be very serious tool as 'expressions of stereotypical invectives or unfounded generalizations' (Mieder, 1993:X). In terms of functions, proverbs have been observed to occur in all communication events and their occurrences proved to be of great significance due to their influence and their effectiveness. They are used in oratory, counseling, judging, embellishing, speeches and enriching conversations (Finnegan, 1994: 36).

First of all, proverbs had and still have a didactic function. By using them we wish to teach people, give them some advice, help in difficult situations, show people what are the most important things in life, show the proper way in life. Most proverbs having a didactic function originate as 'Seek and you shall find '(ibid). When it comes to their significance in communication, it can be clearly seen that Proverbs are very often used in personal interaction. They can function as warning ('Keep your weather eye open', 'Mind your $P^{\prime} s$ and $Q$ 's' ), suggestion ('Live and let live', 'It is never too late to learn'), scolding ('He that seeks trouble, never misses it', 'He struts like a peacock'), explanation ('He who lives by the sword dies by the sword'), justification ('Too many cooks spoil the broth'), a summary or a comment ('Learn wisdom by the follies of others', 'Care killed the cat'). They also bring out the essence of a given phenomenon, warn of danger, tell people how to behave and how to not behave, advise or give direct orders and prohibitions. With the aid of proverb one can aim to provide an endorsement to his statement or opinions, forecast something, express doubts, accuse someone of something, jeer at somebody's misfortune, justify or excuse somebody. Proverbs are also used to sum up life experiences and let the listener draw conclusions by himself and apply them to his behaviour in the future. Mostly, the use of proverbs is deemed significant at various communicative events. They are considered an impressive and influential tool by means of which it is possible to bring into disrepute or mock someone or criticise someone or a situation. Using politeness, in a short, pithy sentence we can hide our own thoughts and say something we would not dare to say in a direct manner. By means of proverbs we can depict wide range of basic people's experiences and problems of modern life in a satirical and moralising way. We would say 'A good husband makes a good wife' if we hear a man complaining about his wife while we know it is not only her fault. In modern writings function of proverbs differs a little bit from that of traditional ones. (Mieder,1993:71). In the process of communication, it is to be observed that the use of proverbs has been defined as way of saying something implicitly rather than explicitly supporting the arguments in popular wisdom which means that the significance of their use is so crucial if an efficient and creative communication is to be achieved.

\section{CONCLUSION}

Linguistically, proverbs are groups of words which maybe a phrase or a sentence expressing a concise and complete thought. They are of various types and comprise all fields of life. Irrespective of their variety, they implicitly have multiple speech acts which are in most cases indirect. The words which compose proverbs have several indications and vary in accordance with the used proverb in a given situation. The most significant aspect of proverbs is the fact that they are used to perform specific aspect in the communicative process. Their functions in language are of great importance as they urge actions, increase knowledge and draw the attention to 
facts and truths. In communication, their significance appears to be a crucial part of human interactions, conveying ideas, emphasizing meanings and so on. The understanding of proverbs, their use and their communicative significance are an essential part of an efficient language understanding and, hence, an efficient language use.

\section{Bibliography}

[1] Akmajian, A.; R. Demers; A. Farmer and R. Harnish. (2001). Linguistics: An Introduction to Language and Communication. Cambridge: The MIT Press.

[2] Finnegan, Ruth (1994). Proverbs in Africa. In: Mieder, Wolfgang /Dundes, Alan (eds.): The Wisdom of many. Essays on the Proverb. London: 10-42.

[3] Leech, G. (1980).Semantics Harmondsworth: Penguin Books limited.

[4] Gairns, R. and Redman, M. (1986). Working with Words. Cambridge: Cambridge University Press.

[5] Moon, P. (1997). Traditional Maori Proverbs: Some General Themes. Auckland: Auckland Institute of Technology.

[6] Whiting, Bartlett, J. (1983). Proverbs in Earlier English Drama with Illustration from Contemporary French Plays. Cambridge Mass: Harvard University Press: New York; Octagon Books

[7] Stiles, W. (1980) "Classification of Intersubjective Illocutionary Acts ". In Language in Society1, pp. 233-249

[8] Vershueren, J. (1999). Understanding Pragmatics. London: Arnold.

[9] Mieder, W. Mieder, Wolfgang. 1993. Proverbs are never out of season: Popular Wisdom in the Modern Age. Oxford: Oxford University Press.

[10] Mieder, W. (2004). Proverbs: A Handbook. Greenwood: Folklore Handbooks. Norrick, N. (1985).How Proverbs Mean: Semantic Studies in English Proverbs.

[11] Berlin: Mouton Publishers.

- $\quad$ Makkai, A. (1984). Commonly Used American Idioms. New York:

[12] Barren's Educational Series, Inc.

[13] Palmer, F. (1981). Semantics. Cambridge: Cambridge University Press.

[14] Taylor, Archer. (1996). The Study of Proverbs. Cambridge: Cambridge University Press 